\title{
Saúde da Família e cuidados paliativos infantis: ouvindo os familiares de crianças dependentes de tecnologia
}

\author{
Family Health and infant palliative care: \\ listening the relatives of technology dependent children
}

Claudia Azevedo Ferreira GuimarãesRabello ${ }^{1}$

Paulo HenriquedeAlmeida Rodrigues ${ }^{2}$

${ }^{1}$ Instituto Nacional de Câncer. PraçaCruz Vermelha 23, 50 andar, Bairro de Fátima. 20230-130 Rio deJaneiro RJ. claudiaafgrabell@terra.com.br ${ }^{2}$ UniversidadeEstácio deSá.
Abstract This study discusses the creation of a new child palliative care program based on the Family $\mathrm{H}$ ealth Program, considering the level of care at home and yielding to family requests. Eighteen members of ninefamilies of technology de pendent children (TDC) who were hospital patients in the Instituto Fernandes Figueira (IFF) participated on the study. From those four were being assisted by its palliative care program Programa de Assistência Domiciliar Interdi sciplinar (PADI); three were inpatients waiting for inclusion in the program, and finally two inpatients already included in PADI. PADI was chosen because it is the only child palliative care program in Brazil. The results are positive in regards to the connection established between the families and the health care team, the reception of the children, the explanation to the family concerning the disease, and the functional dynamics between the PADI and the IFF. As negative points, difficulties aroseas a result of the implementation of the program, from its continuity to the worsening or illness of the entire family. In conclusion, although the PADI is the IFF's way of discharging patients, the domiciliary care provided by the Family H ealth Program, well articulated with the healthcare system, would be ideal for being the adequate assistance for it.

Key words Palliative care, $\mathrm{H}$ ome care, Family Health
Resumo 0 estudo discuteum modelo decuidados paliativos infantis baseado na Saúde da Família quando da assistência domiciliar, articulado com os demais níveis de atenção e nas demandas das famílias. Participaram do estudo dezoito membros de nove famílias de crianças do Instituto Fernandes Figueira (IFF), das quais quatro estão assi stidas pelo Programa de Assistência Domiciliar Interdisciplinar (PADI), três internadas aguardando a inclusão no programa e duas internadas ejá pertencentes ao PADI. O PADI foi estudado por ser o único que oferece cuidados paliativos infantis na redepública de saúde. Os resultados demonstramse positivos quanto ao vínculo estabelecido com a equipe, ao acolhimento, ao conhecimento pelos familiares acerca da doença e à dinâmica entre 0 PADI eo IFF. Como pontos negativos aparecem as dificuldades, que vão desde a implantação do programa até sua continuidade; quase todos os familiares referem agravos ou doenças. Concluiu-se, que apesar de o PADI se apresentar como a forma encontrada pelo IFF para a desospitalização, os cuidados domiciliares pela Saúde da Família, bem articulado com a rede, seriam o ideal por se tratar do nível de assistência adequado para tal.

Palavras-chave Cuidados paliativos, Cuidados domiciliares, Saúde da Família 
Introdução

0 desenvolvimento da tecnologiana área de saúde vem pondo em xeque, entre outros aspectos, questões como a finitude e a qualidade do viver de acordo com M oura ${ }^{1}$ e Schramm². Se a tecnologia pode, por um lado, acelerar o processo de cura, por outro leva ao prolongamento da vida ou à manutenção desta, muitas vezes sem qualidade. Segundo Barreto e Carmo ${ }^{3}$, o desenvolvimento do ramo da neonatologia propiciou o aumento nas taxas de sobrevivência de prematuros e de portadores de anomalias congênitas, dando origem ao surgimento dos chamados "fiIhos da tecnologia" ou crianças dependentes de tecnologia (CDT), portadores de doenças crônicas eque necessitam de vários artefatos para prolongar a sobrevida.

Persiste uma dificuldade, entretanto, na aplicação da terminologia "cuidados paliativos" às crianças e aos adolescentes, tais como as CDT, uma vez que o termo emergiu na atenção oncológica a pacientes terminais. Essa dificuldade possivel mente se refletena ausência de oferta desses cuidados por parte da rede pública brasileira de assistência à saúde no nível da atenção primária ou básica, principalmente quando o locus é 0 domicílio.

Partimos do pressuposto de que o conceito e o oferecimento dos cuidados paliativos devem ser destinados tanto às CDT como às outras doenças incuráveis e crônicas e que, pela proximidade da filosofia e atribuições contidas na legislação, a atenção básica, através do Programa Saúde da Família (PSF), deve ser a responsável pelos cuidados paliativos quando realizados no domicílio, assistindo não só as crianças mas, pre cipuamente, os familiares, que não são alvo de cuidado específico pelo sistema de saúde em um programa de cuidados paliativos.

Este artigo visa apontar alguns subsídios que sustentem a possibilidade de atuação do PSF na oferta de apoio adequado às famílias das crianças sob cuidados paliativos, como também auxiliar na assistência desses cuidados quando realizados em domicílio, em comunicação com a rede de assistência à saúde.

\section{M etodologia}

0 desenvolvimento do trabalho envolveu, além de revisão da literatura e das normas, uma pesquisa qualitativa, com análise de conteúdo por Bardin ${ }^{4}$. A pesquisa foi feita com famílias relaci- onadas ao Programa de Assistência Domiciliar Integrada (PADI), do Instituto Fernandes Figueira (IFF), no Rio de aneiro. O PADI, criado em 2001, visa oferecer atendimento domiciliar para crianças dependentes de tecnologia tratadas pelo IFF, através de equipe multidisciplinar ${ }^{5}$.

0 desenvolvimento do estudo envolveu os seguintes procedimentos: visitas para observação da dinâmica familiar e aplicação de roteiro de entrevista semiestruturada, precedida do devido Termo de Consentimento Informado, para ouvir os familiares com parentesco por afinidade ou consanguinidade. Foram desconsiderados outros moradores, mesmo que desempenhem função de cuidador. Os cenários de investigação foram: os espaços domiciliares referidos pelo PADI e os espaços de internação do IFF. O grupo pesquisado foi composto de familiares e cuidadores de pacientes com diagnósticos variados, sendo a amostra escolhida al eatoriamente e com base no percurso realizado pelo PADI para as visitas domiciliares. Todos os entrevistados são residentes no Estado do Rio de Janeiro, atendidos pelo PADI ou aguardando sua inclusão nele.

Foram entrevistadas pessoas de nove famílias (dezoito pessoas), assim subdivididas: quatro famílias com crianças sob internação domiciliar, três famílias com crianças em internação hospitalar aguardando a inclusão no PADI eduas famílias com crianças internadas, mas já inclusas no PADI.

Em atendimento ao que dispõe a Resolução n ${ }^{\circ}$ 196/96 do CNS ${ }^{6}$, este estudo teve sua aprovação pelo Comitê de Ética em Pesquisa do IFF.

\section{Cuidados paliativos \\ e crianças dependentes de tecnologia}

Um dos princípios do Sistema Ú nico de Saúde (SUS) estabelece a integralidade de assistência, entendida como "conjunto articulado e contínuo das ações eserviços preventivos ecurativos, individuais e coletivos, exigidos para cada caso em todos os níveis de complexidade do sistema" Lei $\mathrm{n}$ 0 8.080/90, art. 70, $1 \mathrm{I}^{7}$. A formulação deste princípio não ampara, expressamente, os cuidados paliativos, que não se enquadram nem nas ações preventivas nem nas curativas, devendo sua fundamentação ser buscada através de outros dois princípios, o da qualidade de vida e o da dignidade da pessoa humana contido no art.10, III da CRFB $/ 88^{9}$, além de um novo sentido da integralidade da assistência que se baseia no cuidado segundo $\mathrm{M}$ attos $^{10}$. 
0 modelo de atenção à saúde, que ainda enfatiza as ações curativas, precisa adotar um novo paradigma, no qual a doença não somente écurável mas também "tratável", o que se faz sentir sob a ética do cuidado. Vale ressaltar, neste sentido, as palavras de Schramm ${ }^{11}$ : "permitiu-se praticamente estabilizar-se muitas doenças terminais [...] e com isso, surge também uma nova atmosfera ao redor do morrer".

A origem dos cuidados paliativos se deu na Idade M édia, constituindo-se no principal tipo de cuidado oferecido pelas instituições hospitalares religiosas até 0 século XVIII. M ais recentemente, em 1967, Saunders introduziu uma nova concepção dos cuidados especializados para pacientes terminais desenvolvidos em unidades especiais denominadas hospices ${ }^{12}$. H oje, os cuidados paliativos não implicam um lugar específico para se morrer, mas uma filosofia aplicada a serviços prestados onde quer que o paciente se encontre, inclusive no espaço domiciliar.

Como assinala Figueiredo ${ }^{13}$, "a denominação 'doente fora de recursos terapêuticos de cura' é, portanto, mais apropriada, pois senão há cura, o alívio dos sintomas, ou conforto e o consolo são ainda possíveis". A expressão pacientes fora de possibilidades terapêuticas atuais (FPTA) é a mais apropriada por permitir englobar, desde 0 tratamento dos pacientes internados, atéos atendidos em ambulatório para controle da sintomatologia, principalmente, a dor, e em domicílio, caso houvesse esse tipo de assistência.

No Brasil, o único instrumento legal - Portaria GM /M Sn $02.439 / 2005^{14}$ - , queinstitui os cuidados paliativos, apenas o faz no bojo da atenção oncológica, deixando de fora uma gama de outras doenças e sujeitos, que necessitam de igual maneira desses cuidados ede políticas públicas queos auxiliem, principalmente no quetangeàs crianças.

Em relação às $C D T$, deve-se mencionar queo United States O ffice of Technology Assistance (US OTA), em documento de 1987, as classifica como aquel as que necessitam ao mesmo tempo de dispositi vo médico para compensar a perda deuma função vital e de cuidado substancial e contínuo de enfermagem para prevenir a morte ou futuras disfunções ${ }^{15}$.

Neste artigo consideramos como semelhantes 0 cuidado dispensado às CDT e às crianças com câncer, já que as demandas e necessidades parecem ser as mesmas, seja quando não se obtém a cura e se põe diante da terminalidade da vida, seja quando a vida só seja viável utilizando tecnologias. Ambas as crianças estão sob cuidados paliativos.
Cunha ${ }^{16}$ mostra que no campo da neonatologia as unidades de terapia intensiva "produziram uma grande contradição, pois ao mesmo tempo que contribuem para a redução das taxas de mortalidade criaram uma nova 'geração' de crianças". Em razão deste tipo de situação, que também ocorre com pacientes de outras faixas etárias, começou a surgir, na década de 1980, uma política voltada para a chamada home care, ou atenção domiciliar (AD).

Nota-se que, no Brasil, tanto as crianças dependentes de tecnologia como as crianças com câncer que estão em cuidados paliativos, que geram uma grande demanda emergente, não são contempladas com programas de saúde ou sociais; tampouco há estudos epidemiológicos que demonstrem tal realidade. Cunha ${ }^{17}$ comenta: "No contexto brasileiro, no entanto, essas crianças parecem permanecer à margem dos serviços, como que invisíveis, no interior das famílias eno meio social mais amplo" (grifo nosso). Não se conta no Brasil com dados que permitam avaliar quantas crianças vivem em condições limítrofes de vida ou sobrevivendo por uso de tecnologia, o que por sua vez contribui para o quadro de negligência no oferecimento desse tipo de tratamento e na assistência aos familiares.

Apesar de a política do SUS propor um modelo de desospitalização, conforme documentos citados a seguir, há ainda o predomínio do modelo hopitalocên trico ${ }^{18}$, e o tipo de cuidados paliativos oferecidos nos hospitais às crianças éinadequado - em geral, por não considerar o espaço domiciliar como um forte aliado, já que os grandes institutos brasileiros, a exemplo do Instituto Nacional de Câncer (Inca), só o oferece aos adultos ${ }^{19}$. Entendemos que 0 modelo ideal de cuidados paliativos deve englobar todas as fases da doença e deve ser instituído desde o seu diagnóstico, em conjunto com o tratamento clínico, indo até o pós-luto, quando em caso de pacientes terminais, conforme propõem Wolfeet al. ${ }^{20} \mathrm{e} \mathrm{Himelstein} \mathrm{et} \mathrm{al.} .^{21}$. A família e o cuidador familiar do paciente sob cuidados paliativos também não são objeto de cuidados e proteção pelos serviços de atenção domiciliar existentes, os quais estão relacionados ao nível terciário, como já se viu, até porque este não éo nível de atenção adequado para esta finalidade.

No Brasil, vêm sendo editadas normas sobre a AD, como por exemplo: o documento do Ministério da Saúde (M S) "1997, o Ano da Saúdeno Brasil, Ações e M etas Prioritárias"22; a Portaria GM /M S n 2.416/199823; a Lei no 10.424/200224; a Portaria SAS/M S n ${ }^{\circ} 249 / 2002^{25}$ e a Portaria GM / 
MS n ${ }^{0} 2.439 / 2005^{14}$. Só esta última aponta para a necessidade dearticulação entreos níveis deatenção e também para que os cuidados paliativos, quando da assistência domiciliar, devem ser de responsabilidade da atenção básica.

As iniciativas concretas de programas de AD existentes no Brasil não estão integradas ao Programa Saúde da Família, como é o caso do Programa de Internação Domiciliar (PID), do Programa de Assistência Domiciliar (PAD), implantados em alguns municípios, como M arília (SP), Santos (SP) e Londrina (PR), apontados por Silva et al. ${ }^{26}$, edo próprio PADI/IFF aqui analisado. Em algumas experiências internacionais de cuidados paliativos, como as do Canadá e da Espanha, aquel es cuidados sefazem junto à atenção primária, como mostram Rehem e $\operatorname{Trad}^{27}$, e Insalud/Esad ${ }^{28}$, respectivamente, apesar de o sistema de saúde canadense ser total mente público. Ambos apresentam problemas em proporções bem menores que o Brasil, em relação a seus financiamentos e critérios de inclusão nos programas, dentre outros. N estes também não há um programa de cuidados paliativos exclusivo para crianças.

O PADI se apresenta como uma alternativa que o IFF encontrou para amenizar o tratamento de crianças em condições crônicas no seu domicílio, porém a equipe de atendimento não é exclusiva deste, haja vista ele não ser cadastrado pelo M inistério da Saúde; comporta o atendimento de no máximo oito crianças e há problemas para suas inclusões, tais como condições de moradia, necessidade de equipamentos e insumos, dentre vários 5 .

\section{O Programa Saúde da Família e cuidados pal iativos}

Os cuidados paliativos devem ter íntima ligação com a saúde da família, porque os familiares são tanto sujeitos importantes no processo de cuidado como também merecedores e carecedores deste. 0 próprio Sistema Único deSaúde(SUS) coloca a internação domiciliar como uma diretriz para a equipebásica de saúde - Lei ${ }^{\circ} 10.424 / 2002^{24}$ - a fim de proporcionar o cuidado integral dos usuários em seu domicílio, pela proximidade com a família e com a busca do apoio intersetorial necessário, já que trabalha diretamente com a noção do chamado "território comum", mencionado por Silva eM ascarenhas ${ }^{29}$, além de buscar fortalecer o seu vínculo com a comunidade e fazer com quea rede desaúde funcione a partir da aten- ção básica, através da referência e contrarreferência e da oferta organizada ${ }^{18}$.

As famílias dos pacientes sob cuidados paliativos pediátricos vivem um processo arrastado de doença de um de seus componentes. Segundo Tavares e Takeda ${ }^{30}$, "O paciente nunca fica doente sozinho, mas toda a sua família adoece junto". Numa pesquisa realizada no Instituto Nacional deCâncer (Inca) no ano de 2004 por Chaves $^{31}$, na unidade destinada aos cuidados paliativos oncológicos em adultos ( $\mathrm{HCIV}$ ) detectou-se que a maioria dos cuidadores eram familiares (92\%) e do sexo feminino ( $96 \%$ ), equeo processo deadoecimento deum membro da família altera diretamenteseus cotidianos por apresentar vários agravos, tais como: cansaço físico (44\%), emocional $(76 \%)$, estresse ( $40 \%)$ e problemas de saúde (28\%). Stone et al. ${ }^{32}$ também encontraram dados semelhantes: os cuidadores costumam ser familiares e amigos ( $86 \%$ ) e do sexo feminino (75\%).

Em geral, as pesquisas que envolvem os familiares apenas o fazem com adultos ou com os cuidadores familiares de crianças e adolescentes com doenças oncológicas. Também os poucos estudos que envolvem familiares das CDT não trazem como preocupação fundamental a assistência à saúde direcionada à família. Segundo $\mathrm{H}$ imelstein et al.$^{21}$, a família deve ser considerada como uma entidadeúnica nos programas decuidados paliativos.

Dessa forma, torna-seurgenteconhecer o que acontece com os familiares de outras crianças sob cuidados paliativos, comparando os dados, apresentando alternativas de como tratá-las efetivamente e do papel da rede de saúde neste contexto. Deacordo com o quetraz a literatura científi$\mathrm{ca}$, de que a mai oria dos cuidadores são familiares e do sexo feminino e do conhecimento de algumas demandas familiares, permite-se a priori sugerir que o modelo de saúde da família representado pelo PSF é o que melhor está juridicamente estruturado para isso ${ }^{33}$.

\section{Resultadosediscussão}

A pesquisa constatou o predomínio das doenças congênitas que envolvem o sistema nervoso central (quatro crianças) eo predomínio das crianças entre a fase lactente e pré escolar (cinco crianças com menos de cinco anos), todas (nove crianças) com dependências tecnológicas semelhantes (gastrostomia, traqueostomia, medicamentos de uso contínuo e dieta industrializada), além da necessidade de oxigenoterapia ou ventilação não 
invasiva (BIPAP), conformea definição deKirk ${ }^{34}$. Nota-se que, por possuírem enfermidades crônicas, necessitam de apoio de uma equipe para assisti-las em domicílio, e em muito ajudaria o auxílio das equipes do PSF em comunicação com o instituto, haja vista que a equipe do PADI está ligada a ele ${ }^{5}$, mas só comportando 0 atendimento de no máximo oito crianças; não está cadastrada no M S edepende do financiamento do IFF.

Devem ser ressaltadas as seguintes características dos pacientes e seus familiares: (1) a presença de irmãos menores em cinco famílias, sendo que em duas as crianças doentes encontramse internadas e ainda não inclusas no PADI; (2) três crianças encontravam-se internadas, praticamente desdeo nascimento; e (3) a Baixada Fluminense como o principal local de moradia - 0 que dificulta 0 acesso do PADI e do fluxo da família para o hospital. Dos dezoito familiares entrevistados, a maioria era do sexo feminino (quinze); o papel de cuidador principal foi desempenhado pela mãe (oito), seguido das avós (três). Suas idades variaram entre 18 e 39 anos e entre 38 e 66 anos, respectivamente. Este predomínio das mulheres como cuidadoras é compatível com informações encontradas na literatura.

A penas cinco entrevistados possuem renda oriunda do próprio trabalho, sendo um autônomo, três com vínculo empregatício e um aposentado. Os demais entrevistados não mais trabalham e, quando o faziam, exerciam atividades informais. Todas as mães são cuidadoras principais, sendo queseis delas tiveram que deixar seus empregos e apenas duas nunca trabalharam. A escolaridade dos entrevistados variou entre o nível técnico (três entrevistados) até o analfabetismo (um entrevistado), sendo predominante 0 ensino médio incompleto (treze entrevistados). A penas um entrevistado terminou o ensino mé dio. As dificuldades para trabalhar em razão do papel como cuidadores somou-se à baixa escolaridade, tendo forte impacto sobre a economia doméstica.

A análise de conteúdo das entrevistas foi feita com base nas seguintes categorias: (1) conhecimento sobre a complexidade da doença; (2) benefícios e desafios da assistência domiciliar; (3) necessidades edificuldades dosfamiliares; (4) conflitos familiares; e (5) agravos edoenças referidas.

Com base na primeira delas, pôde-se verificar como a comunicação entrea equipe e a família é fundamental tanto para o processo do cuidado com a criança doente quanto para a amenização de seus sofrimentos e preven ção de agravos. Devemos lembrar que apesar de as ações educativas terem prioridade no processo de promoção à saúde, não são de competência exclusiva da aten ção básica e não devem objetivar apenas o trei namento técnico da família. Os estudos deWolfeet al.$^{20}$ no âmbito internacional demonstram haver falhas na comunicação quando se compararam os dados obtidos pelas falas dos parentes das crianças com câncer após seus óbitos, relativos à sintomatologia, com os dos prontuários. N este ponto, o papel do PSF é fundamental para dar continuidade às ações educativas iniciadas na alta complexidade, além de cuidar efetivamente da família e do cuidador.

Ainda de acordo com os autores supracitados, as ações educativas também representam um dos principais eixos dos cuidados paliativos, já que além do dever de preparar os familiares para o auxílio aos cuidados exige-se a eticidade nesteprocesso, devendo a equipefavorecer o exercício da autonomia. Os depoimentos dos pais e de outros familiares demonstraram o conhecimento da doença, nem sempre importando o nome técnico do diagnóstico ou dos sintomas, tampouco o grau de instrução que possuem. Como o processo de comunicação/percepção também depende de outros fatores (aceitação, capacidade intelectual, religião, dentre outros) e éindividual, percebem-seapenas al gumas nuances distintas entre os entrevistados. A maior parte dos pais cujas crianças estavam sob assistência domiciliar demonstraram conhecer bem a doença de seu(sua) filho(a).

Pôdeseverificar queentreasfamílias decrianças internadas há mel hor conhecimento por parte de todos os entrevistados, não havendo diferenças que permitam apontar que a comunicação dirigida aos familiares das crianças em assistência domiciliar seja melhor em relação àquelas. Isto pode estar associado a al guns fatores como 0 estabel ecimento de elos com alguns membros da equipe do hospital e a troca de informações com pais de outras crianças que estão em condições semelhantes à de seu parente, devido ao longo tempo de internação das crianças. D eve-se destacar que a percepção sobre a gravidade da doença émais presenteentrefamiliares com crianças atendidas pelo PADI do que em crianças não inclusas nele, o que mostra a necessidade de pessoal especialmente treinado para lidar com os familiares.

Foi observado que 0 entendimento sobre a complexidade da doença apreendido pelos familiares estudados é bem distinto do que revelam os estudos feitos por Lima ${ }^{35}$ com pacientes oncológicos. Vale dizer que, embora tais estudos se deram em contextos distintos, dizem respeito ao 
mesmo objeto: crianças em cuidados paliativos. Nestes, aparece como agravante o longo tempo entreo diagnóstico eo início do tratamento, além defal has de comunicação em relação ao controle da sintomatologia e à possibilidade da morte. Os pacientes do IFF, vinculados ou não ao PADI, tiveram melhor compreensão da doença em re lação a esses estudos com crianças com câncer.

0 perfil institucional eo processo de cronicidade das doenças são fatores que podem explicar tais diferenças. Enquanto o câncer aparece em qualquer fase de idade da criança, as CDT se correlacionam fortemente com alterações genéticas ou prematuridade, sendo, por isso, frequentemente diagnosticadas logo após o nascimento. Desta forma as famílias podem se apropriar gradativamentedesse conhecimento a ponto de não existirem diferenças marcantes, independentemente de estarem sendo atendidas, ou não, no domicílio.

A categoria" "ben efícios e desafios da assistência domiciliar" permitiu avaliar os possíveis benefícios da $A D$. Verificaram-se vários pontos de convergência entre os discursos das famílias quando os próprios comparam o período de internação até o ingresso no PADI. Sobressaem a noção de maior gasto econômico com transporte e 0 maior desgaste físico e emocional, fazendo crer na ideia dequeo PADI na vida dessas famílias foi um divisor de águas. Também fica clara a noção do vínculo com a equipe e a corresponsabilização no processo do cuidado, semel hante ao que é preconizado pela política do PSF ${ }^{33}$.

Em relação aos discursos dos familiares de crianças internadas e não inclusas no PADI, há evidências que apontam para a dificuldade de acesso, al guns desgastes com a equipe hospitalar e a ausência de serviços de saúde próximo ao bairro em que residem.

N ota-se que existem elementos semelhantes entre o PADI e os demais modelos de assistência domiciliar apontados anteriormente pelos estudos de Silva et al. ${ }^{26}$ eo modelo espanhol no quetangeà necessidade de alguns critérios e condições para admissão neles. Tais elementos de certa forma excluem uma parcela de indivíduos e apresentam-se como desafios na sustentação dos programas.

Já as famílias queestão com a criança ou adolescente internados, e já são assistidas em domicílio, enfatizam o fortalecimento da relação com osirmãos e a facilitação para cuidar também dos outros filhos.

Apesar de o modelo do PADI não estar ligado à atenção básica, mas apenas voltado para a de manda exclusiva do IFF, adota el efilosofia seme Ihante à do PSF, o que nos permite aferir os be- nefícios e aplicá-los anal ogicamente. Esses dados poderão servir de alicerce para a fundamentação ecriação de um programa de assistência domiciliar que esteja voltado para os cuidados paliativos infantis e que abarque outras doenças além do câncer e da população adulta.

Há carência de estudos empíricos que confirmem o desejo dos familiares de que as crianças em cuidados paliativos sejam assistidas em casa, o que foi percebido como afirmativo pelo presente estudo e que pode servir, neste sentido, de ponto de partida para novas pesquisas. Alguns estudos realizados no âmbito internacional mencionados por Lima ${ }^{35}$ apontam alguns benefícios semelhantes ao PADI, tais como maior liberdade emenor alteração da dinâmica familiar; mastambém divergências em relação aos seus benefícios, como dificuldade para readmissão hospitalar e preocupação com o tipo de suporte que se receberia em seus domicílios. No grupo estudado do PADI, estes dois últimos elementos não foram mencionados por nenhum entrevistado; pelo contrário, os pais demonstram grande segurança em relação a eles, exceto quanto à dificuldade de transporte de urgência.

Com base na categoria "necessidades e dificuldades dos familiares", a análise revelou os principais desafios para implantação de programas de atenção domiciliar. Foram detectados problemas tanto pelos que têm assistência domiciliar pelo PADI quanto pelos que não a têm em relação à ausência ou insuficiência de: estratégias de apoio; referência e contrarreferência; continuidade do cuidado; e dificuldades para implantação do PADI. Todas as famílias têm ou tiveram que obter os equipamentos e insumos necessários através da Justiça com ações ajuizadas pela Defensoria Pública. Este ponto evidencia, além de um desrespeito ao direito à saúde, uma divergência entre o discurso do Ministério da Saúde favorável à desospitalização ${ }^{23,24}$ eà humanização ${ }^{36}$ e o que de fato se verifica.

Da mesma forma, a intersetorialidade e a comunicação com os outros níveis de assistência mostraram-semuito débeis ou inexistentes, o que ajuda a explicar o fato de que o IFF, ao criar o PADI, desistisse de buscar apoio de outras instâncias. Cunha ${ }^{17}$, Leite ${ }^{37}$ e M endes ${ }^{38}$ apontam dificuldades semelhantes de apoio às CDT pelos diferentes níveis de atenção - todos os estudos basearam-se em crianças em cuidados paliativos, apesar de contextos distintos.

Outras dificuldades encontradas dizem respeito ao aumento das despesas com energia elétrica; à complementação de atendimento fisiote- 
rapêutico próximo à residência para as crianças que mais necessitam; às condições das moradias para a implantação do PADI; às despesas com alimentação adequada para as necessidades das crianças quando da alta hospitalar; e, por fim, à dificuldade para o reingresso, principalmente da mãe, no mercado de trabalho e na escola, por falta de apoio de creches públicas com cuidadores especializados.

A utilização da categoria "conflitos familiares" surgiu da observação da dinâmica familiar. Afinal, a presença deuma criança ou adolescente com doença crônica ou incurável podelevar a desajustamentos familiares, pois precipita ou acentua desequilíbriose conflitos no interior da dinâmica familiar. Os principais sentimentos apontados pelos entrevistados foram o sentimento de perda diante da possibilidade da morte e nas relações familiares; privações econômicas e da liberdade pessoal; e a negação da incurabilidade da doença, dados também encontrados no estudo de Leite ${ }^{37}$.

Os conflitos familiares foram relacionados pe los entrevistados às seguintes situações: queda da renda familiar; dificuldades para reingressar nos estudos e no trabalho; e problemas de saúde de outrosfamiliares. Duas das mães de crianças internadas enão inclusas no PADI denotaram sensação de abandono e desordens emocionais evidenciadas, principalmente, pela ruptura do cuidado com os demais filhos, e problemas de dimensão social, como dificuldades financeiras edelazer, evidenciados pela longa permanência no hospital. Elas também referiram conflitos como sensações de cul pae tristeza. Em relação a essas famílias, encontraramse, ainda, diferenças no trato com os demais filhos menores, que foram mais acentuadas entre os casos de internação prolongada, sendo bem mais amenas quando em assistência domiciliar eem relação às famílias com crianças com câncer, diferente, quanto a estas últimas, do que também apontaram os estudos de Lima35.

A categoria "agravos familiares e doenças re feridas" ajudou a avaliar a influência de fenôme nos que podem potencializar a ocorrência de danos à saúde, com base no conceito ampliado de saúde e no artigo $3^{\circ}$ da Lei $n^{\circ} 8.080 / 90^{7}$, que considera as condições sociais como primordiais na redução dos riscos. 0 recurso ao termo "doenças referidas" visou valorizar as doenças e os sintomas apontados pelos entrevistados, mas não submetidos à confirmação diagnóstica. Todos os familiares entrevistados referiram algum tipo dedoença decunho emocional ou físico. Em alguns casos, os problemas foram referidos por outros familiares que não o próprio, como: epi- sódios de ocorrência de "dor no peito"; alcoolismo; e a não submissão a exames derotina, inclusive o preventivo de câncer de colo uterino.

Quase não foi mencionada a situação de saúde dos outros irmãos, embora eles tenham aparecido como alvo de preocupação em alguns momentos (não cumprimento dos prazos de vacinação, impossibilidade de comparecimento a consultas pediátricas de rotina). Outro fator destacado pelos familiares foi a tristeza dessas crianças em razão do sentimento dedistância em relação aos pais e ao(à) irmão(ã) doente. A negligência com a própria saúdeesteve mais associada à falta de tempo pelo desempenho de função de cuidador principal. As principais doenças referidas e agravos entre os familiares foram: hipertensão arterial, obesidade e transtornos emocionais (depressão, estresse, tristeza e perturbação do sono).

Com a exceção de uma, todas as cuidadoras principais entrevistadas referiram maior número de doenças e agravos, mostrando-se, portando, mais vulneráveis e com necessidade de assistência, havendo poucas diferenças em relação ao acesso e aos riscos de desenvolverem doenças entre as cuidadoras cuja criança já esteja inclusa no PADI eas demais. A vigilância da saúdedessas pessoas poderia ser mais efetiva se os cuidados paliativos domiciliares fossem oferecidos pelo PSF bem estruturado.

\section{Consideraçõesfinais}

Os cuidados paliativosno Brasil ainda são oferecidos, prioritariamente, por meio de programas vinculados a instituições hospitalares, mesmo quando há um programa domiciliar, e dirigidos aos adultos. Esses programas, além de se mostrarem inadequados para atender às necessidades de crianças e adolescentes, da mesma forma o são para atender às necessidades dos seus familiares.

No Brasil ainda não há programas específicos de cuidados paliativos e continuados que as contemplem, com base na atenção primária, e que articulem os diferentes níveis de complexidade da atenção, apesar de o PSF atender crianças e familiares dentro de sua clientela adstrita. Alguns dos poucos programas de assistência domiciliar existentes, apesar de estarem ligados, de alguma forma, à atenção primária, não têm elo com o PSF - como acontece com o PAD e 0 PID, referidos no texto, e com o próprio PADI.

Nos programas existentes, por conta das características aqui apontadas, prevalece a dicoto- 
mia de concepção saúde/doença fundada no modelo hegemônico, hospitalocêntrico, curativo e individual, apesar de eles estarem voltados para a desospital ização e a humanização e de seu modelo estar baseado na aplicação de tecnologias leves. A atenção básica deve exercer um papel fundamental também nos cuidados continuados, crônicos ou paliativos, conforme sinaliza a OM S ${ }^{39}$, devendo ser o principal responsável pela atenção aos pacientes e seus familiares e a base para o sistema de referência e contrarreferência, de forma a assegurar a articulação da continuidade dos cuidados nos demais níveis de atenção, conforme propõe $M$ endes ${ }^{18}$.

Alguns dos problemas encontrados no PADI não são diferentes dos encontrados nos demais programas de assistência ou internação domiciliar: dificuldades de financiamento; manutenção do programa; referência e contrarreferência; e com relação à intersetorialidade. Esses programas, ao serem implantados sem o vínculo com a atenção básica ou primária, tendem a enfrentar tais problemas porque 0 sistema de saúde ainda funciona de forma invertida à al mejada: no sentido da alta complexidade para atenção primária, o que não ocorre com outros model os internacionais como no Canadá e na Espanha, mencionados no texto.

Este estudo buscou identificar os principais agravos e doenças referidas pelos familiares e cuidadores, revelando que os cuidadores principais estão mais expostos aos riscos. O PADI não se apresentou como capaz de interferir diretamente no processo saúde/doença dos familiares de forma eficaz. Não houve diferenças importantes em termos das manifestações de sintomas por parte das famílias cuja criança esteja em assistência domiciliar ou hospitalar, fato queaponta para a necessidade de que esse cuidado deva ser feito pelo PSF.

Através da análise temática realizada, ficou patente que se o PADI oferece, por um lado, um serviço de qualidade para os seus beneficiados, deixa de fora, por outro, uma parcela importanteque se mantém hospitalizada, por só comportar 0 atendimento de, no máximo, oito crianças. Também os familiares envolvidos acabam por adoecer, já que não é sua finalidade precípua a assistência à saúde destes últimos.

As ações educativas real izadas pelo PADI, bem como o processo de comunicação/percepção por ele desenvolvida, mostraram ter resultados significativos ao permitir melhor compreensão sobre a complexidade da criança doente. I sto tem grande sintonia com a filosofia dos cuidados paliati- vos, contribuindo para amenizar o sofrimento e auxiliando as famílias a lidarem com a realidade.

Conforme pudemos observar, as demandas apresentadas pelos familiares são de diversas ordens, esão agravadas pela incongruência entre o discurso ea prática da saúde, em particular em relação ao atendimento domiciliar. Como seviu, o não oferecimento dos meios necessários tem levado as famílias a recorrer ao Poder Judiciário, o que contribui para a ocorrência de desgastes emocionais, desperdício detempo erecursos, inclusive públicos.

A análise dos discursos mostrou que há fatores que dificultam a inclusão de muitas crianças no PADI, como problemas com moradia, necessidade de equipamentos e insumos, dentre outros. Em relação às crianças já inclusas no PADI, verificaram-se problemas com gastos de energia elétrica, medicamentos ealimentação. A ausência tanto de apoio de creches eescolas para os irmãos dos pacientes como de pessoas especializadas no cuidado impede o retorno do cuidador ao trabaIho e causa impacto na economia doméstica.

Os resultados da pesquisa reforçam a defesa do PSF como espaço ideal para 0 atendimento de boa parte das demandas familiares. Como se viu, o modelo espanhol parece estar mais próximo do que é proposto neste artigo, talvez pela semel hança do que propõe o modelo do PSF no Brasil e pela semelhança entre os seus sistemas de saúde. M esmo não existindo um programa específico para crianças, lá os cuidados paliativos são oferecidos pela atenção primária, deacordo com o perfil demográfico da clientela adstrita a determinada área.

Há grande necessidade de desenvolvimento deestudos epidemiológicos sobreas crianças que sobrevivem em situações limítrofes de vida e dependentes datecnologia. Fica claro que estaéuma parcela "invisível" da população, conforme afirma Cunha ${ }^{17}$, sendo mantida escondida, com características de grupo excluído, que precisa ser enxergado pela ótica da integralidade.

Estegrupo representa um grande impacto nos custos do sistema de saúde, em razão tanto da dependência de tecnologia quanto desua permanência no ambiente hospital ar ${ }^{38}$. Por todas as razões expostas anteriormente, este problema deveria se constituir numa preocupação importante das autoridades na área da saúde pública brasileira, vindo a gerar ações mais efetivas na organização do sistema com controle de gastose menores custos.

A organização dos cuidados continuados domiciliares a partir da atenção básica earticula- 
da aos outros níveis de complexi dade da atenção exigiria integrar, ainda, tecnologia e humanização, a partir do encontro da tecnologia "dura" com a tecnologia "leve" e da alta complexidade com a atenção primária ${ }^{18}$.

Ao se transferir a responsabilidade do cuidado para os familiares daquilo que é produto da tecnologia e fora de seus domínios, emergem sobrecargas emocionais, sociais efinanceiras, que somente podem ser amenizadas por ações educativas que priorizem a autonomia, 0 acolhimento e o suporte social. Como o PSF trabalha com os conceitos de promoção de saúde, prevenção de doenças, controle de agravos e intersetorialidade, possivelmente poderia contribuir para amenização desses impactos, necessitando de algumas transformações profundas em sua implementação pelos municípios.

Gostaríamos de enfatizar que ao defendermos um programa de assistência domiciliar na atenção básica voltado aos cuidados paliativos infantis, o qual também atenda às demandas das famílias, pretendemos que ele deva muito mais ser pautado na ótica da integralidadee da humanização do que, simplesmente, na política de descongestionamento dos leitos e redução de custos, sob pena de retrocedermos a um modelo de saúde utilitarista e reducionista.

\section{Colaboradores}

CAFG Rabello e PHA Rodrigues participaram, igualmente, de todas as etapas de elaboração do artigo.

\section{Referências}

1. Moura MM. São muitos os remédios para os males dessa vida: análise de recursos terapêuticos a partir da doença crônica na infância [dissertação de mestrado]. Rio de Janeiro: Instituto de M edicina Social, Universidade do Estado do Rio de Janeiro; 2001.

2. Schramm FR. Bioética e moralidade das biotecnologias. In: Emenick MC, Valle S, Costa MAF, organizadores. Gestão biotecnológica: alguns tópicos. Brasília: Ed. UnB; 1996. p. 123-130.

3. Barreto $M L$, Carmo $E$. Velhos e novos males da saúde no Brasil: a evolução do país e suas doenças. São Paulo: Hucitec; 1995.

4. Bardin L. Análise de conteúdo. Lisboa: Edições 70; 1977.

5. Brasil. Ministério da Saúde. M anual de orientação do Programa de Assistência Domiciliar Interdisciplinar - PADI. Rio de Janeiro: Instituto Fernandes Figueira/Fundação Oswaldo Cruz; 2001.

6. Brasil. Conselho Nacional de Saúde. Resolução nº 196/96. Dispõe sobre ética em pesquisa em seres humanos. [acessado $2006 \mathrm{abr}$ 7]. Disponível em: http://www.saude.gov.br

7. Brasil. M inistério da Saúde. Lei n 8.080, de 19 de setembro de 1990. Dispõe sobre as condições para a promoção, proteção e recuperação da saúde, a organização e o funcionamento dos serviços correspondentes e dá outras providências. [acessado 2006 fev 2]. Disponível em: http://www.saude.gov.br
8. M inayo M CS, Hartz ZMA, Buss PM. Qualidade de vida e saúde: um debate necessário. Cien Saude Colet 2000; 5(1):7-17.

9. Brasil. Constituição da República Federativa do Brasil de 1988. Organização dos textos, notas remissivas e índices por Cláudio Brandão de Oliveira. 9a ed. Rio de Janeiro: DPEA; 2001.

10. M attos RA. Os sentidos da integralidade: algumas reflexões acerca de valores que merecem ser defendidos. In: Pinheiro R, Mattos RA, organizadores. Os sentidos da integralidade na atenção e no cuidado à saúde. Rio de Janeiro: IMS-Uerj, Abrasco; 2001. p. 39-64.

11. Schramm FR. M orte e finitude em nossa sociedade: implicações no ensino dos cuidados paliativos. Revista Brasileira de Cancerologia 2002; 48(1):17-20.

12. Pessini L. A filosofia dos cuidados paliativos: uma resposta diante da obstinação terapêutica. In: Pessini L, Bertachini L, organizadores. Humanização e cuidados paliativos. São Paulo: Editora Loyola; 2004. p. 181-208.

13. Figueiredo MTA. Conceito: princípio e filosofia de cuidados paliativos. In: Teixeira MJ, Figueiró JAB, organizadores. Dor: epidemiologia, fisiopatologia, avaliação. São Paulo: Grupo Editorial Moreira Jr.; 2001. p. 400-403.

14. Brasil. Ministério da Saúde. Portaria GM n².439, de 8 de dezembro de 2005. Institui a política de Atenção Oncológica. [acessado 2006 abr 3]. Disponível em: http://www.inca.gov.br 
15. Haffner JC, Schurman SJ. The technology-dependent child. Pediatrics Clinics of N orth America 2001 48:751-764.

16. Cunha SR. A enfermeira e a família da criança dependente de tecnologia: a intermediação dos saberes [dissertação de mestrado]. Rio de Janeiro: Escola de Enfermagem Anna Nery, Universidade Federal do Rio de Janeiro; 1997.

17. Cunha SR. A enfermeira-educadora, as M arias e 0 José: tecendo a rede de saberes e práticas sobre o cuidado à criança dependente de tecnologia na comunidade [tese]. Rio de Janeiro: Escola de Enfermagem Anna Nery, Universidade Federal do Rio de Janeiro; 2001.

18. M endes EV. Um novo paradigma sanitário: a produção social da saúde. In: Mendes EV, organizador. Uma agenda para a saúde. São Paulo: Hucitec; 1996. p. 233-300.

19. Brasil. M inistério da Saúde. Cuidados paliativos/ CSTO/HC IV. [acessado 2006 nov 23]. Disponível em: http://www.inca.gov.br

20. Wolfe J, Grier HE, Klar N, Levin SB, Ellenbogen JM, Susanne Salem-Schatz S, Emanuel EJ, Weeks JC. Symptoms and suffering at the end of life in children whit cancer. New England Journal of Medicine 2001; 342:12-21.

21. Himelstein BP, Hilden JM, Boldt AM, Weisman D. Medical progress: pediatric palliative care. N ew England Journal of M edicine 2004; 17(350):1752-1762.

22. Brasil. M inistério da Saúde: 1997, o ano da saúde no Brasil: ações e metas prioritárias. Brasília. [acessado 2007 ago 5]. Disponível em: http://www.saude.gov.br

23. Brasil. M inistério da Saúde. Portaria GM n².416, de 16 de março de 1998. Estabelece os requisitos para credenciamento de hospitais e critérios para realização da internação domiciliar no SUS. [acessado 2007 set 6]. Disponível em: http://www.saude.gov.br

24. Brasil. Ministério da Saúde. Lei $n^{\circ} 10.424$, de 15 de abril de 2002. Acrescenta capítulo e artigo à Lei $n^{\circ}$ 8.080, de 19 de setembro de 1990, que dispõe sobre as condições para a promoção, proteção e recuperação da saúde, a organização e o funcionamento de serviços correspondentes e dá outras providências, regulamentando a assistência domiciliar no Sistema Ú nico de Saúde. [acessado 2007 set 6]. Disponível em: http://www.saude.gov.br

25. Brasil. M inistério da Saúde. Portaria SAS no 249, publicada em 16 de abril de 2002. Estabelece 0 atendimento domiciliar como modalidade de assistência ao idoso. [acessado 2006 abr 3]. Disponível em: http://www.saude.gov.br

26. Silva KL, Sena R, Leite JCA, Seixas CT, Gonçalves AM . Internação domiciliar no Sistema Ú nico de Saúde. Rev Saude Publica 2005; 39(3):391-397. [acessado 2005 ago 18]. Disponível em: http://www.scielo.br

27. Rehem TCM SB, Trad LAB. Assistência domiciliar em saúde: subsídios para um projeto de atenção básica brasileira. Cien Saude Colet 2005; 10(Supl.): 231-242. [acessado 2007 fev 6]. Disponível em: http:/ /www.scielo.br

28. Instituto Nacional de Salud (Insalud). Equipos de Soporte de Atención Domiciliaria (Esad). Programa de Cuidados Paliativos a Domicilio, Atención primaria, Areas 2 y 5. Zaragoza: Insalud/Esad; 1998.
29. Silva JAG, M ascarenhas TM . Avaliação da atenção básica em saúde sob a ótica da integralidade: aspectos conceituais e metodológicos. In: Pinheiro R, M attos RA, organizadores. Cuidado: as fronteiras da integralidade. Rio de Janeiro: Hucitec, Abrasco; 2004. p. 241-258.

30. Tavares $M$, Takeda S. A prática da atenção primária à saúde. In: Duncan BB, Schmidt MI, Gugliani ERJ, organizadores. Medicina ambulatorial: condutas clínicas em atenção primária. Porto Alegre: Artmed; 1996. p. 29-35.

31. Chaves ARM. O cuidador no provimento do cuidado ao paciente com câncer avançado no Instituto Nacional de Câncer. Revista Brasileira de Cancerologia 2006; 52(1):111-114.

32. Stone R, Cafferata GL, Sangl J. Caregivers of the frail elderly: a national profile. The Gerontologist 1987; 27(5):616-626.

33. Brasil. M inistério da Saúde. Saúde da família: uma estratégia para a reorientação do modelo assistencial. Brasília: M inistério da Saúde; 1997.

34. Kirk S. Families experiences of caring at home for a technology-dependent child: a review of the literature. Child: Care, Health and Development 1998; 24:101-114.

35. Lima, RAG. Experiências de pais e de outros familiares de crianças e adolescentes com câncer: bases para os cuidados paliativos [tese de livre-docência]. Ribeirão Preto, São Paulo: Escola de Enfermagem de Ribeirão Preto, Universidade de São Paulo; 2002.

36. Brasil. Ministério da Saúde. Política Nacional de Humanização (PNH), Humaniza SUS, 2004. [acessado 2007 maio 18]. Disponível em: http:// www.saude.gov.br

37. Leite NSL. A família da criança dependente de tecnologia: organização para sobrevivência [dissertação de mestrado]. Rio de Janeiro: Pós-Graduação em Saúde da Criança e da Mulher, Instituto Fernandes Figueira, Fundação Oswaldo Cruz; 2003.

38. M endes RAGCS. Programa de Assistência Domiciliar Interdisciplinar do Instituto Fernandes Figueira: limites e possibilidades na construção de uma prática integral no cuidado à criança dependente de tecnologia [dissertação de mestrado]. Rio de Janeiro: Pós-Graduação em Saúde da Criança e da Mulher, Instituto Fernandes Figueira, Fundação Oswaldo Cruz; 2005.

39. Organização Mundial da Saúde (OMS). Cuidados inovadores para condições crônicas: componentes estruturais de ação: uma estratégia em serviços de saúde para todo o Brasil. Braślia: Organização M undial da Saúde; 2003.

Artigo apresentado em 06/06/2007

A provado em 23/10/2007

Versão final apresentada em 05/12/2007 